\title{
Representação social da qualidade de vida de idosos com doença pulmonar obstrutiva crônica
}

\section{Social representation of quality of life of elderly with chronic obstructive pulmonary disease}

\author{
Maria Carolina da Silva Cardoso Nanque, Eliane Maria Ribeiro de Vasconcelos
}

Como citar este artigo: NANQUE, MARIA C. S.;

VASCONCELOS, ELIANE M. R. Representação social da qualidade de vida de idosos com doença pulmonar obstrutuva crônica. Revista Saúde (Sta. Maria). 2019; 45 (3)

\section{Autor correspondente:}

Nome: Maria Carolina da Silva

Cardoso Nanque

E-mail: nanquecarolina@gmail.com

Telefone: : (8I) 998302040

Formação Profissional: Mestre em Cerontologia pela UFPE,

Especialista em fisioterapia gerontolódica pela Associação

brasileira de fisioterapia gerontológica (ABRAFICE)/

Conselho federal de fisioterapia

e terapia ocupacional e

Bacharel em Fisioterapia pela

(o)Universidade Federal de

Pernambuco UFPE, Recife, PE, Brasil

Filiação Institucional: Unifavip/wyden Caruaru-Pernambuco

Endereço para correspondência: Cidade: Recife

Estado: Pernambuco

CEP: 52051-395

Data de Submissão:

06/05/2019

Data de aceite:

|4/1|/2019

Conflito de Interesse: Não há conflito de interesse

\section{(cc) BY-NC-ND}

\section{RESUMO}

O envelhecimento humano é um fenômeno sócio demográfico que tem sido observado nas discussões sobre as estruturas sociais no contexto da saúde, educação e cultura. Aalteração do padrão demográfico é acompanhada da alteração do perfil epidemiológico e, neste cenário, as doenças crônicas não transmissíveis assumem uma posição de destaque. A doença pulmonar obstrutiva crônica é altamente incapacitante e seu caráter progressivo e crônico mostra para um declínio substancial da qualidade de vida dos indivíduos acometidos. A representação social traduz qualitativamente os símbolos pelos quais a população com DPOC aprende, a lidar com as mudanças ocorridas pela doença que interfere diretamente na qualidade de vida, tanto no contexto individual quanto no coletivo. 0 objetivo foi Investigar a representação social da qualidade de vida de idosos com Doença Pulmonar Obstrutiva Crônica. $O$ caminho metodológico tramitou-se dentro de um estudo descritivo com abordagem qualitativa. A população do estudo foi constituída por idosos com diagnóstico confirmado de doença pulmonar obstrutiva crônica assistidos pelo ambulatório de pneumologia do Hospital das Clínicas da Universidade Federal de Pernambuco. Foi realizada uma entrevista semi-estruturada para a coleta dos discursos individuais, a análise dos dados se deu através do software IRAMUTEQ. Obteve-se como resultados que os conteúdos representacionais dos entrevistados estavam ancorados nos conceitos construídos e compartilhados pelos mesmos através do estabelecimento de suas relações sociais, organizadas a partir das experiências vividas, sejam elas de modo individual ou interpessoal, e estas com o mundo exterior. A experiência relatada pelos participantes acerca da qualidade de vida na DPOC demonstra o quão eles se percebem lesados pela doença e, de certo modo, sem esperança. Ressaltase que os conteúdos representacionais sobre a qualidade de vida na DPOC estão objetivados nas repercussões sintomatológicos da doença, como o cansaço, a crise, a incapacidade de realização de atividades que dantes eram possíveis, na dependência de uma rede de apoio, na perda de autonomia, no sofrimento, na tristeza, na ansiedade e na perda da esperança. Concluiu-se que as vivências desse grupo, dentro do contexto familiar íntimo e também no coletivo, sofrem bastante modificação.

PALAVRAS-CHAVE: Idosos; Representação social; DPOC; Qualidade de vida.

\section{ABSTRACT}

Human aging is a socio-demographic phenomenon that has been observed in discussions about social structures in the context of health, education and culture. The change in the demographic patern is accompanied by a change in the epidemiological profile and, in this scenario, chronic noncommunicable diseases take a prominent position. Chronic obstructive pulmonary disease is highly disabling and its progressive and chronic character shows for a substantial decline in the quality of life of affected individuals. The social representation qualitatively translates the symbols by which the population with COPD learns to deal with the changes that occur through the disease that directly 
interfere in the quality of life, both in the individual and in the collective context. The objective was to investigate the social representation of the quality of life of the elderly with Chronic Obstructive Pulmonary Disease. The methodological path was constructed within a descriptive study with a qualitative approach. The study population consisted of elderly patients with a formal diagnosis of chronic obstructive pulmonary disease, assisted by the pneumology clinic of the Hospital das Clínicas of the Federal University of Pernambuco. A semi-structured interview was conducted to collect the individual speeches and the data analysis was done through IRAMUTEQ software. It was obtained as results that the representational contents of the interviewees were anchored in the concepts constructed and shared by them through the establishment of their social relations, that is, they were organized from the lived experiences, be they in an individual or interpersonal way, and these with the outside world. The experience reported by participants about quality of life in COPD demonstrates how they perceive themselves injured by the disease and, to a certain degree, hopeless. It is emphasized that the representational contents on the quality of life in COPD are objectified in the symptomatic repercussions of the disease, such as fatigue, crisis, inability to perform activities that previously were possible, depending on a support network, in the loss of autonomy, of suffering, of sadness, of anxiety, and of the loss of hope. The experiences of this group, within the intimate family context and also in the collective, undergo much modification.

KEYWORDS: Elderly; Social Representation; COPD; Quality of life.

\section{INTRODUÇÃO}

O envelhecimento é um processo orgânico, natural, gradual e irreversível, no qual ocorrem transformações ao longo da vida. Trata-se de um período complexo, heterogêneo e que está atrelado a diversos fatores, desde genéticos à qualidade de vida, educação e ambiente em que o indivíduo vive e desempenha as suas atividades (OLIVEIRA, 2010). O mundo tem sido palco do envelhecimento populacional, evidenciado, em primeiro plano, pelos países desenvolvidos e, em segundo, pelos países em desenvolvimento. O Brasil tem mudado seu perfil demográfico tornando-se envelhecido. As melhorias nas práticas de saúde pública, o controle de natalidade e programas de planejamento familiar associados à inserção da mulher no mercado de trabalho têm sido fatores protagonistas no aumento da expectativa de vida no contexto nacional (VASCONCELOS, 2012). Segundo a Organização Mundial da Saúde - OMS (2005) estima-se que, até 2025, o número de idosos atinja uma cifra de 32 milhões de pessoas com 60 anos ou mais, sendo o sexto país do mundo em número de idosos.

O Instituto Brasileiro de Geografia e Estatística (IBGE), em 2010, publicou que a população com 80 anos ou mais, segue a tendência mundial de crescimento, alcançando em 2040, a marca de 4,3\% do total de habitantes e, em 2050, chegando a 6,4\% da população. Assim como o perfil demográfico tem tomado novas conformações, passando de um país com maioria expressiva de jovens para uma população senil, o perfil epidemiológico tem acompanhado essas transformações, deixando de apresentar um perfil de doenças infectocontagiosas para assumir um padrão de doenças crônicas não transmissíveis (DUARTE, 2012).

Dentre as múltiplas doenças crônicas não transmissíveis temos a Doença Pulmonar Obstrutiva Crônica (DPOC) que, de acordo com a organização Mundial da Saúde (OMS, 2011), é uma das principais causas de morbidade 
e mortalidade no mundo e representa um desafio à saúde pública. Acredita-se que até 2020 será a quinta doença mais prevalente no contexto mundial. Essa doença é caracterizada por obstrução progressiva e não reversível das vias aéreas, hiperinsuflação pulmonar, inflamação crônica e elevada frequência de exacerbações que cursam com múltiplas comorbidades e efeitos sistêmicos deletérios. O número de mortes devido ao uso do tabaco tem atingido a cifra de 4,9 milhões por ano em todo o mundo, o que corresponde a mais de 10 mil mortes por dia (SHRIKRISHNA, 2012). Os pacientes com DPOC apresentam anormalidades relativas à função pulmonar decorrentes da disfunção de trocas gasosas, perda de massa muscular respiratória e periférica, e alterações na função cardíaca que resultam em dispneia, intolerância aos esforços e reduzida qualidade de vida (REARDON, 2007).

A redução da qualidade de vida se dá pela cronicidade e progressão da patologia que leva a quadros de dependência funcional substancial. O seu tratamento baseia-se no afastamento dos fatores causadores da doença como o tabaco e outros poluentes assim como na reabilitação pulmonar. O tratamento deve ser realizado por uma equipe multiprofissional, dando um caráter holístico na abordagem terapêutica do paciente com DPOC (GOLD, 2015). Não menos importante, deve-se incrementar a educação em saúde com o intuito de tornar o paciente ciente das causas, sintomas e tratamento para que se potencialize a adesão adequada à abordagem terapêutica.

A qualidade de vida segundo a OMS é a percepção do indivíduo de sua posição na vida no contexto da cultura e sistema de valores nos quais ele vive e em relação aos seus objetivos, expectativas, padrões e preocupações ( OMS, 1995). Um modelo conceitual de qualidade de vida,que pode ser pautado em três aspectos: bem-estar, saúde e fatores externos. Bem-estar relaciona-se a uma percepção subjetiva, embasada em valores e crenças individuais, incluindo componentes como: felicidade, satisfação, realização e afetos. Saúde é a dimensão mais importante e traduz a presença objetiva de doença e o impacto subjetivo dos sintomas que a mesma acarreta aos indivíduos. Os fatores externos podem ser os indicadores sociais e representam o aspecto objetivo desta conceituação. (DIMEÑAS ET AL, 2000)

Tendo em vista que a qualidade de vida é um conceito multifacetado e depende de múltiplos aspectos, faz-se relevante o questionamento deste conceito aos próprios pacientes com DPOC. Uma abordagem qualitativa do conceito de qualidade de vida aos indivíduos com DPOC desbravará um terreno desconhecido até então. A investigação sobre o modo pelo qual eles enxergam suas incapacidades e quais são os símbolos que representam suas compreensões acerca de sua qualidade de vida. Para se compreender melhor esse contexto foi escolhida a Teoria das Representações Sociais (TRS) - proposta por Serge Moscovici, em 1961, na sua obra A Psicanálise, sua imagem e seu público -, pois a mesma tem por objetivo explicar fenômenos humanos a partir de um espectro coletivo, sem desprezar o individual. Vale ressaltar que a TRS relaciona-se com o estudo das simbologias sociais e de como os símbolos influenciam a dinâmica e ações humanas, quer individual, quer coletiva. Sendo assim, a TRS coaduna-se com a proposta de investigação do presente trabalho. 


\section{MÉTODO}

\section{Delineamento do estudo:}

Trata-se de um estudo descritivo-exploratório de abordagem qualitativa, baseado na Teoria das Representações Sociais, centralizado na estruturação de conceitos a partir do senso comum.

\section{Local e população de estudo:}

O estudo foi realizado no Ambulatório de Pneumologia do Hospital das Clínicas da Universidade Federal de Pernambuco, localizado na cidade do Recife, Estado de Pernambuco, Brasil. 0 ambulatório dispõe de atendimento médico especializado para pacientes com a Doença Pulmonar Obstrutiva Crônica (DPOC). O espaço físico do referido ambulatório é amplo e existe uma rotina regular de atendimentos estabelecidos semanalmente.

A população foi composta por indivíduos idosos com Doença Pulmonar Obstrutiva Crônica, cadastrados e assistidos pelo Ambulatório de Pneumologia do Hospital das Clínicas da Universidade Federal de Pernambuco. A amostra obedeceu aos critérios de inclusão e exclusão do presente estudo, através da saturação dos dados que aconteceu quando as respostas começaram a se repetir, e nenhuma perspectiva nova foi somada às anteriores, caracterizando uma amostra por conveniência.

\section{Coleta de dados:}

A coleta dos dados aconteceu em quatro encontros, de modo individualizado, durante o mês de dezembro de 2016. O tempo médio de cada encontro foi de 60 minutos. Aos idosos elegíveis foi aplicado, inicialmente, o instrumento mini exame do estado mental (MEEM), que consiste num teste utilizado para avaliar função cognitiva, de forma rápida e de fácil aplicação, esse instrumento consta nos anexos desse projeto. Através deste foi realizado o rastreio através da avaliação de domínios como: orientação espacial, orientação temporal, memória imediata e evocação, cálculo, linguagem, nomeação, repetição, compreensão, escrita e cópia de desenho. Foi um teste validado para o território brasileiro. Posteriormente à aplicação do MEEM deu-se a entrevista, cujo roteiro aborda inicialmente alguns aspectos sociodemográficos como: escolaridade e ocupação. Logo após a abordagem sociodemográfica foram realizados três questionamentos diretamente ligados ao objetivo da pesquisa, onde a partir destes foram colhidos os discursos para posterior análise. Os questionamentos foram:

1) Como o Sr. (a) se sentiu após o diagnóstico da Doença Pulmonar Obstrutiva Crônica (Enfisema Pulmonar/ Bronquite Crônica)?

- $\quad$ 2) Esta doença provocou ou provoca alguma limitação no $\operatorname{Sr}(a)$ ?

- 3) Suas atividades de vida diária e/ou profissionais foram alteradas durante os anos após o diagnóstico? 
A entrevista realizada foi registrada no diário de campo e gravadas com a prévia autorização dos participantes. O instrumento utilizado para gravação foi um aplicativo de gravação de voz executável em microcomputador.O roteiro da entrevista consta nos apêndices deste estudo.

\section{Análise dos dados:}

Após a construção dos dados, os mesmos foram analisados através do programa IRAMUTEQ. O programa é um software gratuito que viabiliza diferentes tipos de análises de dados textuais, desde aquelas bem simples, como a lexicografia básica (cálculo de frequência de palavras), até análises multivariadas (classificação hierárquica descendente, análises de similitude). O programa organiza a distribuição do vocabulário de forma facilmente compreensível e visualmente clara (análise de similitude e nuvem de palavras).

Foi utilizado a análise de classificação hierárquica descendente (CHD) que classifica os segmentos do texto em função dos seus respectivos vocabulários, e o conjunto deles é repartido com base na frequência das formas reduzidas.

\section{Considerações Éticas:}

Foram levadas em consideração as determinações da Resolução Nº 466/2012 do Conselho Nacional de Saúde: Autorização e consentimento dos participantes para o registro, utilização e divulgação das informações obtidas no trabaIho, através do Termo de Consentimento Livre e Esclarecido; explicação dos objetivos, metodologia e cronograma aos participantes e acerca das contribuições do estudo e da sua relevância social, assegurando confidencialidade em todo 0 processo. O presente estudo foi aprovado pelo comitê de ética do Centro de Ciências da Saúde da Universidade Federal de Pernambuco sob o CAAE: 0993416.8.0000.5208.

\section{RESULTADOS E DISCUSSÃO}

O número de participantes obedeceu ao critério de saturação, pois a inclusão progressiva dos significados atribuídos ao fenômeno apareceu com frequência nos discursos das participantes da pesquisa (SALDLER et al., 2010). A pesquisa de campo foi finalizada quando na entrevista não houve acréscimo ao estudo sobre a temática abordada, totalizando a amostra final em cinco idosos com DPOC.Os entrevistados pertenciam à faixa etária de 61 a 78 anos. Quanto à escolaridade, três possuíam ensino médio incompleto e dois, ensino fundamental completo. Entre as ocupações todos eram aposentados no momento da construção dos dados.

A partir da CHD foi dividido em 76 segmentos de texto (ST), relacionando 715 palavras que ocorreram 2666 vezes. A CHD reteve $75,00 \%$ do total de ST, gerando seis classes. Desta forma, a partir da análise da CHD por meio do corpus, o Software explanou essa relação em forma de dendograma das classes (figura 1). 
Figura 1 - Dendograma das classes obtidas a partir do corpus textual. Recife (PE), 2017, Brasil
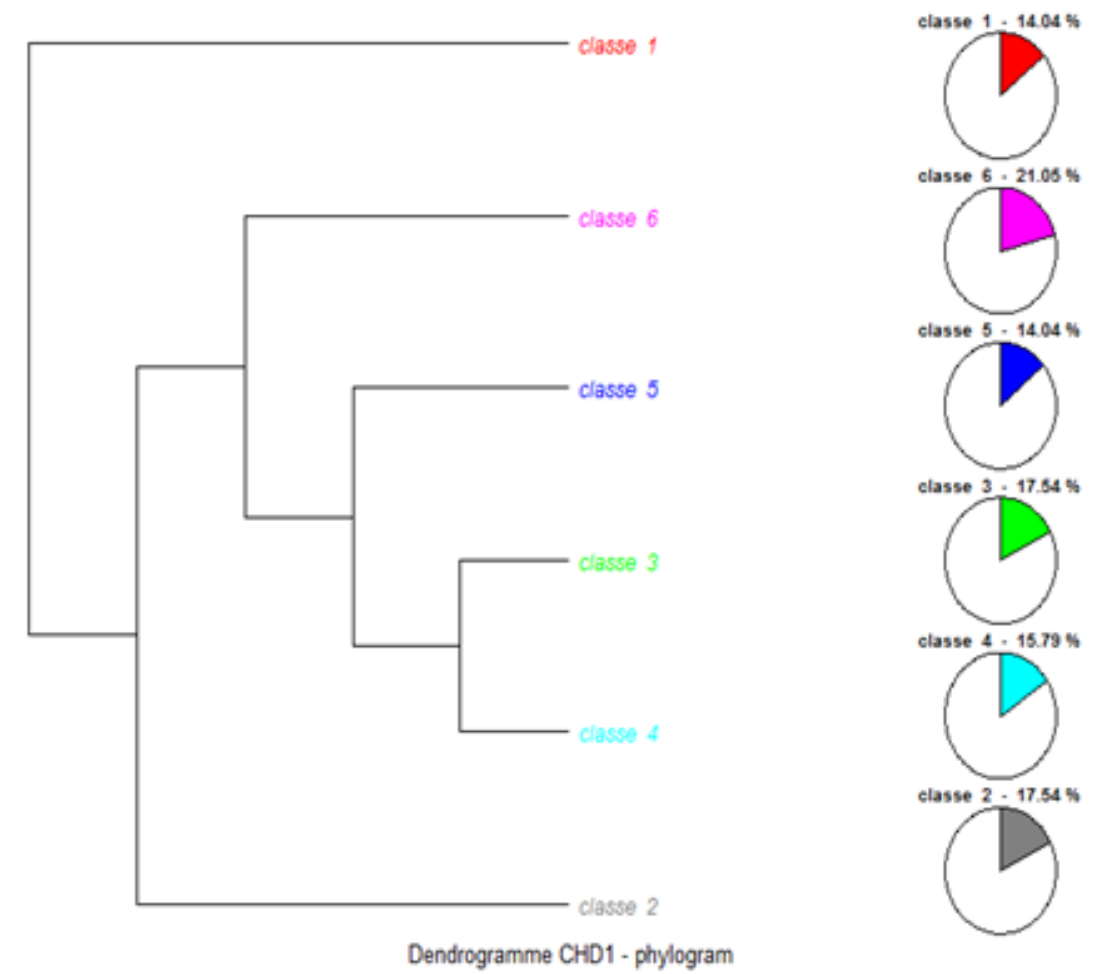

Fonte: Autor (2017)

Para obter as classes finais foram realizadas partições do corpus conforme ilustra este dendograma. Ao se fazer a análise da esquerda para a direita, conforme recomendações, pôde-se observar que na primeira divisão (partição ou interação) o qual o corpus foi sujeito, este foi dividido em dois sub-corpus: o da direita originou a classe 1 e, posteriormente, o subcorpus da esquerda foi dividido em cinco, originando as classes 2, 3, 4, 5 e 6.

Neste estudo, as palavras analisáveis foram distribuídas em seis classes da seguinte forma: classe 1, correspondendo a $14,04 \%$ do total de segmentos de texto; classe 2, correspondendo a $17.54 \%$ do total de segmentos de texto; classe 3, correspondendo a 17.54\%; classe 4, correspondendo a $15,79 \%$ do total de segmentos de texto; classe 5 , correspondendo a $14,04 \%$ do total de segmentos de texto; e a classe 6 , correspondendo a $21,05 \%$ do total de segmentos de texto. Na figura 2 é possível visualizar os resultados de associação de palavras pré-determinadas à qualidade de vida de idosos com DPOC.

Figura 2 - Dendograma das classes de Representações Sociais sobre a qualidade de vida de idosos com DPOC. Recife (PE), 2017, Brasil. 


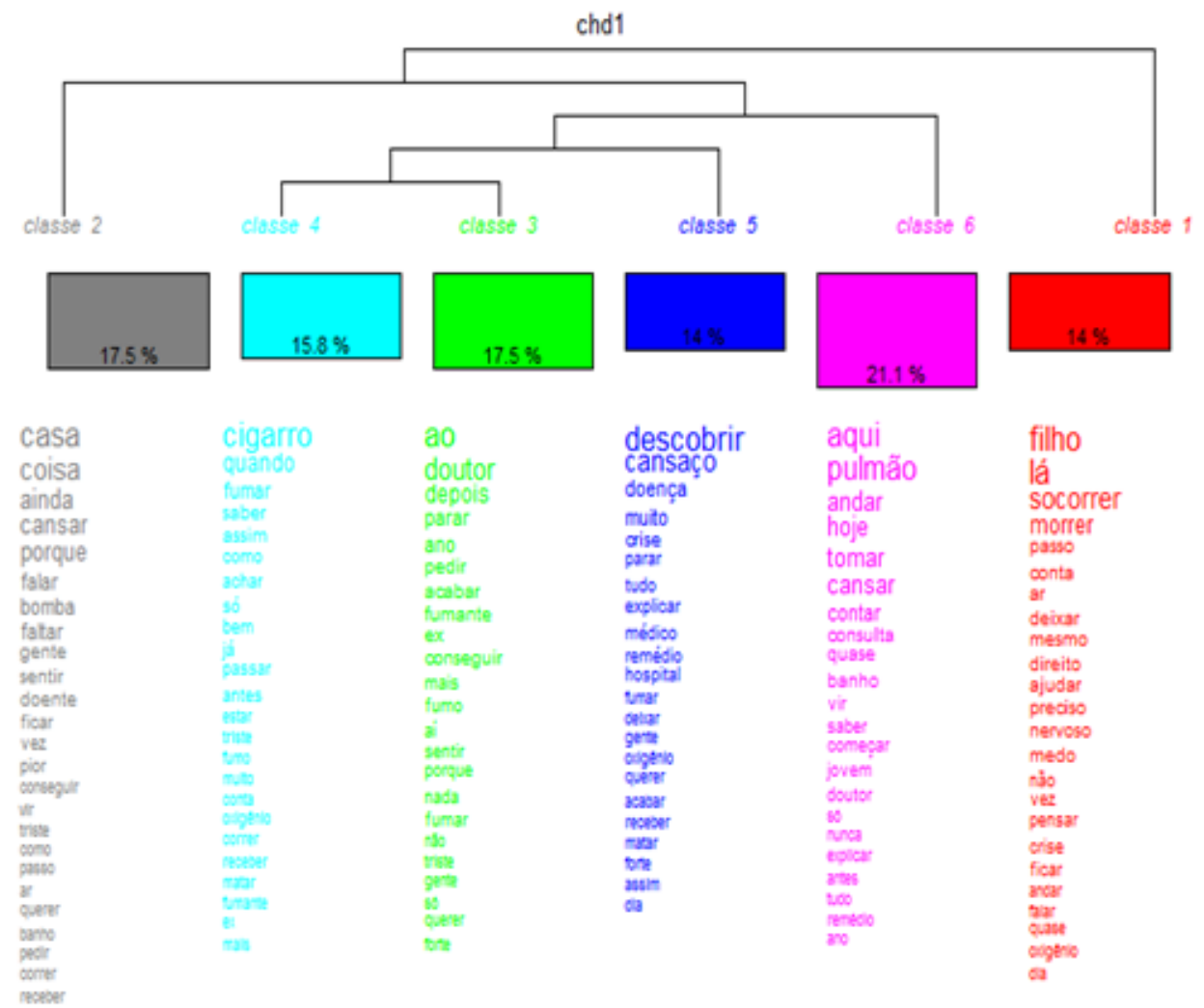

Fonte: Autor (2017)

Após análise, o dendograma deflagra as palavras que emergiram das falas das participantes construídas a partir do senso comum. As informações declaradas pelos entrevistados abordaram aspectos concernentes ao processo da qualidade de vida, no que diz respeito as suas experiências e vivências, quer positivas, quer negativas. Desta forma, ao caracterizarmos as representações sociais da qualidade de vida de idosos com DPOC temos a pretensão e o objetivo de obter conhecimento de senso-comum sobre o fenômeno.

Para análise e discussão dos resultados, houve o acompanhamento das partições da esquerda para a direita conforme o dendograma preconiza, e então as classes foram nomeadas conforme o significado que as mesmas retratam. Devido as semelhanças entre as classes 2 e a 6; e as classes 5 e 3, resolvemos aglutiná-las, aos pares, já que elas se inter-relacionam intrinsecamente. Diante da justificativa de aglutinação, a classe 6 e 2 se juntam e é denominada "Aspectos da intolerância aos esforços e incapacidade funcional". Já as classes 5 e 3 se juntam e é denominada "Descoberta da doença e suas percepções'. A classe 4 denomina-se "Circunstâncias para o início do tabagismo", e, por fim, a classe 1 nomeada "Aspectos concernentes a relação de dependência da rede de apoio". A seguir as classes serão descritas seguindo a ordem de partição e de proporção que representam em relação ao corpus total, adotando-se a CHD.

A classe denominada de "Aspectos da intolerância aos esforços e incapacidade funcional" relaciona-se às atividades que proporcionam incapacidades que a doença impõe diante das atividades de vida diária, as quais os idosos 
com DPOC são expostos. Diante dos esforços exigidos pelas atividades, aflora a sintomatologia da doença como é exposto nos discursos a seguir:

...Mas andar pra longe eu não faço, com medo de passar mal. Quando faço alguma coisa pesada, eu tenho um cansaço que penso que vou morrer. Não faço nenhuma atividade física regular com medo de cansar. Já fui socorrido, com crise de cansaço, algumas vezes depois de fazer umas 'trelas'.

(Idoso 1)

...Eu não faço mais nada, passo o dia assistindo televisão. O pouquinho que ando fico quase sem fala. Meu dia é no sofá. $O$ banho é cansativo. Algumas vezes vestir a roupa também é uma dificuldade...

(Idoso 2)

Eu vou pra todo canto com a 'bomba (broncodilatador)' com medo de cansar e cair. Quando tomo banho canso muito (...). Da minha casa para o centro é mais ou menos um quilômetro, eu paro várias vezes pra descansar porque canso de verdade (...), se eu continuar eu passo mal. Quando tenho esse cansaço até a fala fica cortada. Ultimamente eu não faço nada de esforço na minha casa. Na consulta desse mês eu disse ao doutor que o remédio não tá fazendo mais efeito. Não está passando meu cansaço.

(Idoso 3)

Quando eu era mais jovem eu só cansava quando levava fumaça do fumo, hoje eu canso só de andar. Eu não confio de andar sozinha por conta das crises. Tenho medo de não ter ninguém para me socorrer. Deixei de fazer muita coisa na minha vida: não posso arrumar minha casa, não posso cozinhar porque ficar muito tempo em pé me cansa, não posso varrer casa. Tudo que eu faço vai além das minhas forças. Essa doença me deixa muito preocupada. Cada dia que passa eu faço menos coisas.

(Idoso 4)

Não posso visitar minhas amigas da mocidade, porque se andar muito eu canso. Antes, correr era impossível, agora, nem andar eu aguento. Daqui a pouco vou ficar só deitada na cama.

(Idoso 5)

A intolerância aos esforços demonstrada nos discursos acima refere-se à incapacidade de realizar as atividades de outrora sem "cansar". Os pacientes referem muitas limitações diante de suas atividades de vida diária e até mesmo nas atividades de higiene pessoal. 
A cronicidade da doença imprime fortes limitações nas atividades a médio e a longo prazo; a esse fenômeno chamamos "espiral da dispneia". A espiral de dispneia é a limitação progressiva de atividades que o idoso com DPOC fica exposto, por exemplo: Antes era muito difícil correr cem metros, hoje é difícil andar cinquenta metros, assim por diante (CARDOSO, 2016).

A classe 5 e 3 contraíram aglutinação e denominou-se "Descoberta da doença e suas percepções". Essa classe diz respeito às circunstâncias nas quais ocorreram os primeiros sintomas e a tomada de decisão para procurar ajuda médica até o fechamento do diagnóstico clínico formal da DPOC.

Nos primeiros anos de fumo não sentia nada. Achei estranho quando cansei pela primeira vez. Isso nunca tinha acontecido. Depois veio a tosse e muito catarro. Após a segunda crise, procurei o médico para saber o que tinha(...) O médico me disse que a doença não tem cura e que eu precisava parar de fumar e fazer corretamente o que ele orientasse. Só quando ele falou isso descobri que era sério mesmo.

(Idoso 1)

Eu só vi que o fumo tava me prejudicando com 40 anos. Antes eu não sentia nada, mas depois dos quarenta me sinto pior a cada ano. Sinto-me mais cansada. Desde que descobri essa doença fico mais ansiosa, por conta da sensação de morte que tenho nas crises.

(Idoso 2)

Alguns anos depois de ter começado a fumar, percebi o cansaço e o sufocamento. O cansaço era forte. Procurei o doutor. Descobri a doença depois de alguns anos. Parei de fumar quando tive uma crise muito forte e me levaram pra o hospital. Quando descobri o que eu tinha me assustei, mas, hoje em dia, tento obedecer ao tratamento.

(Idoso 3)

...Eu descobri essa doença devagarinho. As crises de cansaço depois apareceram outras vezes, e parece que, de tempos em tempos, ela volta. Quando a crise volta, parece que volta com mais força.

(Idoso 4)

Tudo começou com muita tosse, depois veio cansaço. No começo o cansaço não era muito forte, dava pra aguentar. Os anos foram passando e eu comecei a me sentir mais cansada para resolver as coisas. Precisei tomar oxigênio algumas vezes. Quando recebi o diagnóstico da doença foi que eu entendi que essa doença é fatal. Sou revoltada por isso!

(Idoso 5) 
Os sintomas de cansaço e fadiga são os primeiros a serem sentidos pelo indivíduo com DPOC. Com o passar dos anos, ao cansaço, soma-se a intolerância aos esforços. Geralmente os sintomas aparecem depois de longos anos de exposição ao cigarro ou poluentes atmosféricos que deflagram a cascata inflamatória. A sensação de incapacidade, traduzida pelo cansaço, faz com que os indivíduos com DPOC procurem ajuda médica e percorram certo caminho até 0 recebimento do diagnóstico formal da doença (CARDOSO, 2016).

A classe 4 "Circunstâncias para o início do tabagismo" deflagra os eventos promotores do primeiro contato desses idosos com a exposição ao cigarro. As falas exprimem certo pesar pela desinformação, na época, dos malefícios do cigarro. Os idosos evidenciam pesar pela falta de maturidade frente as suas decisões, sobretudo sobre a decisão de começar a fumar.

Comecei a fumar pelas influências dos amigos, hoje eu vejo que não eram amigos. Eu me prejudiquei demais; fumava muito, de domingo a domingo, muitos cigarros por dia (...).

(Idoso 1)

Eu era muito pequena no sertão quando comecei a fumar, não sei quantos anos eu tinha, só sei que eu parei quando eu tinha quarenta anos. Acho que fumei mais de 20 anos. Eu fumava cigarro e cachimbo. Fumei, por curiosidade, o cachimbo do meu pai. Como ele não proibiu eu me viciei no fumo (...). Naquela época ninguém sabia que fumar era ruim, na roça não tinha médico (...).

(Idoso 2)

Fumei trinta e três anos. Quando já era tarde percebi que o fumo me sufocava. Fumei até cigarro de papel, se brincar. Eu trabalhava com meu pai em um parque de diversões desde os seis anos de idade. Viajava no meio do mundo. Eu era muito novo ainda, mas mesmo assim tinha que ajudar meu pai. Minha brincadeira de criança era fumar e meu pai deixou. Se meu pai tivesse me batido e me proibido de fumar eu não tava assim (...). Passado não se muda!

Hoje em dia, na televisão, passa o mal do cigarro. No meu tempo ninguém sabia que isso matava aos poucos. Quando eu cresci achava bonito fumar os cigarros caros. Fumar ajudava a me amostrar para os amigos ou para a namorada (...). Quem não fumava não era bem visto.

(Idoso 3)

Fumei por 45 anos. Nas minhas lembranças fumava uma carteira de cigarros por dia. Meu trabalho foi sempre com cal. Engolia a poeira do cal. Naquela época eu era menina pequena. Fumava com as amigas no intervalo do serviço. Era um divertimento pra gente (...)

(Idoso 4) 
Acho que ao todo foram mais de 35 anos de fumo. Comecei a fumar por influência de uma colega que fumava e depois de uma brincadeira me viciei e não parei mais. Acabei achando bonito, charmoso (...)

(Idoso 5)

É notório nos discursos que os mesmos tiveram, algum tipo de influência social, o desejo aflorado de experimentar, pela primeira vez, o cigarro ou o cachimbo. Há algumas décadas atrás, o processo de educação em saúde era muito insuficiente, havia pouca informação sobre os malefícios da exposição ao cigarro e seus possíveis desdobramentos danosos no corpo humano. Fumar, em outras décadas passadas, conferia 'status' social ao fumante. Fumar era um critério de inclusão em alguns segmentos sociais (REIS, 2012).

A classe 1 "Aspectos concernentes a relação de dependência da rede de apoio" deflagra a relação desses idosos com sua rede de apoio. À medida que a doença progride, as limitações aumentam, e consequentemente há o aumento da dependência funcional por parte dos mesmos.

Minha filha e minha mulher fazem todas as coisas em casa, eu fico só na barraca despachando os clientes. Queria ter a força de antes. Ė muito triste não poder fazer as coisas e depender dos outros.

(Idoso 1)

A minha filha resolve tudo pra mim; vai para o banco, compra minhas coisinhas, lava a roupa e limpa a casa. Eu não faço quase nada. Passo o dia assistindo televisão, o pouquinho que tento fazer já me deixa cansada e fico quase sem fala. O povo lá de casa fica apavorado com medo que eu tenha crise. Minha filha já não deixa eu fazer minhas "trelas"(...).

(Idoso 2)

Eu não quero atrapalhar a vida de ninguém, só queria melhorar e fazer minhas atividades pra ninguém ter trabalho comigo (...). Eu preciso que meus filhos me ajudem, mas é chato ficar pedindo, toda hora, para eles fazerem coisas que antes eu conseguia fazer. Eu ainda consigo dirigir (...).

(Idoso 3)

Dependo da minha filha para ir para todos os lugares, ela nem trabalha pra poder ficar comigo. Ela sabe explicar direito o que eu passo. Essa doença apavora a gente. É muito triste (...).

(Idoso 4) 
Minha neta é muito boa pra mim, ela não reclama de nada, mas eu sei que ela queria ser como as colegas dela. Eu prendo muito minha neta. Ela tem responsabilidade de fazer todos os serviços de casa e ainda tem que faltar aula para me levar no médico. Um dia desses fiquei com muita vergonha de chamar minha neta para pentear meu cabelo, porque comecei a desembaraçar e já fui ficando cansada. Ela veio e penteou meu cabelo. Até isso que todo mundo faz eu não consigo fazer. Essa é a pior doença que existe!

(Idoso 5)

As relações de dependência e perda de autonomia geram bastante ansiedade, medo, tristeza e desesperança nesses idosos. Por mais que eles tenham uma rede de apoio que forneça, com presteza, o devido auxílio; eles se sentem lesados quando perdem autonomia diante de suas decisões e de suas atividades, antes corriqueiras. A qualidade de vida está intrinsecamente relacionada aos aspectos de autonomia e independência funcional. Qualquer fator interno ou externo que promova desarmonia nesse binômio afetará objetivamente a qualidade de vida desses indivíduos (MAURER et al., 2009).

ADPOC é uma doença, na maioria das vezes, de mau prognóstico. A doença cursa com múltiplas incapacidades funcionais e perda objetiva de autonomia. A qualidade de vida desses indivíduos encontra-se bastante comprometida; seja pela consciência do prognóstico ruim da doença, seja pela intolerância aos esforços, seja pelo processo de revoltaansiedade-tristeza provocado pela má escolha de começar a fumar, seja pela dependência de uma rede de apoio ou ainda pela perda da capacidade de tomada de decisão (MAURER et al., ibid.). Diante dos discursos expostos percebe-se que os conteúdos representacionais dos entrevistados estavam ancorados nos conceitos construídos e compartilhados pelos mesmos através do estabelecimento de suas relações sociais, ou seja, estiveram organizadas a partir das experiências vividas, sejam elas de modo individual ou interpessoal, e estas com o mundo exterior.

A experiência relatada pelos participantes acerca da qualidade de vida na DPOC demonstra o quão eles se percebem lesados pela doença e, de certo modo, sem esperança. Ressalta-se que os conteúdos representacionais sobre a qualidade de vida na DPOC estão objetivados nas repercussões sintomatológicos da doença, como o cansaço, a crise, a incapacidade de realização de atividades que dantes eram possíveis, na dependência, na perda de autonomia, no sofrimento, na tristeza e na ansiedade. As vivências desse grupo, dentro do contexto familiar íntimo e também no coletivo, sofrem bastante modificação. Há alteração de padrões hierárquicos dentro da família. De repente o homem que era chefe de família e tinha papel deliberativo sobre a mulher e os filhos encontra-se em posição de inferioridade em relação aos mesmos que antes, de certo modo, assumiam papel de subordinação, por exemplo.

A qualidade de vida depende de uma rede de apoio presente, assim como o resgate da autonomia e da independência funcional diante das tomadas de decisão e das atividades de consideradas imprescindíveis no contexto individual e coletivo.( MESQUITA, 2012) 
O indivíduo com DPOC torna-se vulnerável, propenso a desenvolver componentes de ansiedade, ideação suicida, tristeza profunda. (GODOY, 2013). É imprescindível que sejam repensados os modelos de reabilitação pulmonar vigentes. É preciso que os profissionais enxergem além do pulmão, o olhar deve estar voltado para o processo de devolver a esses idosos a vontade de viver. A educação é um dos meios pelos quais esse ideal pode ser alcançado. Idosos que sabem o que é sua doença e as possibilidades terapêuticas tendem a aderir melhor a terapêutica indicada (REIS et al., 2014).

Os indicadores quantitativos se mostram insuficientes para clarificar o fenômeno da qualidade de vida nestes idosos, visto a complexidade dos fatores envolvidos. Ė importante salientar que muitos estudos se limitam exclusivamente a descrição de indicadores sem fazer relações diretas com a qualidade de vida, ou seja, valorizam características como escolaridade, ausência dos sintomas das doenças, condições de moradia unicamente como indicadores de qualidade de vida sem investigar o objetivo disso para as pessoas envolvidas (PEREIRA et al., 2012). 0 modelo de intervenção na DPOC deve ser repensado, assim como devem ser repensados os meios de avaliação da qualidade de vida dos mesmos. Questionários engessados não traduzem as peculiaridades individuais, tampouco são aptos para indicar uma intervenção mais holística.

Práticas integrativas e complementares podem ser uma alternativa terapêutica nos desdobramentos "extrafísicos" ou "metafísicos" da doença como a ansiedade e a depressão. Pereira et al. (ibid.), mostra que numa população de pacientes oncológicos tais práticas repercutiram positivamente nos componentes de ansiedade e depressão. Ainvestigação dos efeitos das práticas integrativas e complementares como intervenção terapêutica associada a um programa de reabilitação pulmonar convencional se faz necessária. A inclusão desses pacientes em programas holísticos, que promovam independência funcional, capacidade funcional, autonomia, auto-cuidados, assimilação de novos papéis sociais são de fundamental importância para a qualidade de vida tanto no contexto individual quanto no coletivo desses idosos.

\section{CONSIDERAÇÕES FINAIS}

O presente estudo conclui que a qualidade de vida dos idosos estudados transpassou asfronteiras dos indicadores provenientes de dados quantitativos demonstrados na literatura científica e atingiu a perspectiva primeiramente do indivíduo. Os constructos da TRS utilizados no presente trabalho, ancoragem e objetivação, evidenciam para os símbolos sobre os quais os indivíduos com DPOC constroem sua percepção individual e coletiva sobre a doença e seus desdobramentos, sobretudo no que concerne o aspecto da qualidade de vida. A sintomatologia deflagrada pela doença, como a dispneia, a intolerância aos esforços, a dependência de uma rede de apoio intrinsecamente atrelada à severidade 
e progressão da doença, serve como o aparador sobre o qual a ancoragem e a objetivação transitam para a construção do senso comum, que explica a qualidade de vida para os mesmos, e depois, por uma via sequencial, esses indivíduos transformam suas percepções, como em um interminável ciclo, onde o velho serve de "retalho" para o novo e o novo torna-se velho, numa reconstrução constante, parafraseando Moscovivi. Agora um novo mundo se abre, e com ele, um horizonte de possibilidades de intervenções terapêuticas para melhorar a qualidade de vida dessa população. 0 presente estudo esmiúça os sentimentos, expõe as sensações, define os transbordamentos e permite conhecer a fundo o que é qualidade de vida para esta população.

Para um entrevistado, qualidade de vida é conseguir pentear os cabelos; para o outro, é não incomodar os filhos diante de uma tarefa considerada "fácil"; para outros, apesar de dizer através dos seus símbolos que sua qualidade de vida era ruim, ainda exclamou:" eu ainda consigo dirigir", como forma de expressar: Ainda me resta uma fração de qualidade de vida.

O profissional de saúde precisa suplantar a frieza dos números e dos processos fisiopatológicos e investigar, com afinco, os outros determinantes, muitas vezes não mensuráveis, mas que desprendem um impacto tão danoso quanto à deficiência da alfa-1-antitripsina, composto responsável pela deflagração da cascata inflamatória na DPOC, nessa população.

\section{REFERÊNCIAS}

1. ANDERSON, K.L. The effect of chronic obstructive pulmonary disease on quality of life. Res Nurs Health, Rockville Pike, v.32, n.2, p.44-46. 1995.

2. BIRMAN, J. Estilo e modernidade em Psicanálise. São Paulo: editora 34. 1995.

3. CAMPOLINA, A. G. A., SANTOS, F., LEBRÃO, J. L. F., ML. A transição de saúde e as mudanças na expectativa de vida saudável da população idosa: possíveis impactos da prevenção de doenças crônicas. Cad saúde pública, Rio de Janeiro, 29(6): 1217-29, 2013.

4. CARDOSO, M. C. S., SAYÃO, L. B., SOUZA, R. M. P., MARINHO, P. É. M. (2016). Pulmonary rehabilitation and wholw-body vibration in chronic obstructive pulmonary disease. Motriz, Rio Claro,V.22 N.2, p. 36-42. 
5. COSTA, N. E., MESQUITA, R. A. V., Carvalho, H. B.C. D de \& Freitas, E. V. de et al.( orgs).(2011). Políticas Públicas de Saúde para o Envelhecimento e Velhice. Tratado de Geriatria e Gerontologia,1614-1620.(3ªed). Rio de Janeiro(RJ): Guanabara Koogan

6. DIMENÄS, E.S., DAHLÖF, C.G., JERN, S.C., WIKLUND, I.K.. Defining quality of life in medicine. Scand J Health Care 1990; Suppl 1:7S-10S.

7. DUARTE, E. C., BARRETO, S. M. (2012). Transição demográfica e epidemiológica: a Epidemiologia e Serviços de Saúde revisita e atualiza o tema. Epidemiologia. Serv. Saúde v.21 n.4 Brasília.

8. FARQUHAR, M. Definitions of quality of life: a taxonomy. Journal of Advanced Nursing, Oxford, v.22, n.3, p.502-8, 1995.

9. FLECK, M. P. A. O instrumento de avaliação de qualidade de vida da Organização Mundial da Saúde (WHOQOL-100): Características e perspectivas.Ciência e Saúde Coletiva, 5(1):33-38, 2000.

10. FONSECA, A.P.C; PEREIRA, C.F. et al. Reabilitação Pulmonar na Doença Pulmonar Obstrutiva Crônica. ACTA FISIATRICA 3 (2): 18-22. 1996.

11. GLOBAL strategy for the diagnosis, management and prevention of copod, Global initiative for Chronic Obstructive lung Disease (GOLD 2015). Disponível em: http://www.goldcopd.org/ acesso no dia 20 de abril de 2016.

12. GOLDFARB, D. C. Corpo, tempo e envelhecimento. São Paulo: Ed. do Psicólogo. 1997.

13. GODOY, R. F. de. Ansiedade, depressão e desesperança em pacientes com doença pulmonar obstrutiva crônica. Rev. de Estudos e Pesquisas em Psicologia. v.13, n.3. 2013.

14. GUARESCHI, P.A., JOVCHELOVITCH S. Textos em representações sociais. 2. ed. Petrópolis: Vozes; 1995.

15. INSTITUTO BRASILEIRO DE GEOGRAFIA E ESTATÍSTICA - IBGE. Censo demográfico 2010. Rio de Janeiro (RJ): IBGE, 2012. 
16. KERKOSKI, E., BORENSTEIN, M. S., GOLÇALVES, L. O., FRANCIONI, F. F. Grupo de convivência com pessoas com doença pulmonar obstrutiva crônica: sentimentos e expectativas. Texto e contexto Enfermagem, Florianópolis, 2007 abr-jun; 16(2): 225-32.

17. LOYOLA FILHO, A. I. de et al. Causas de internações hospitalares entre idosos brasileiros no âmbito do sistema único de saúde. Epidemiologia e Serviço de Saíude, Brasília, v.13, n.4, p.229-238, dez. 2004.

18. MARTINS, H.H.T.S. Metodologia qualitativa de pesquisa. Educação e Pesquisa. 2004.

19. MARQUES, C.P. Envelhecimento no Brasil: da formulação de políticas à estruturação de serviços de saúde integrais. Tempus, actas de saúde colet. Brasília. V.8, n.1,p. 65-70. mar, 2014.

19. MENDES, M.R.S.S.B, et al, A situação social do idoso no Brasil: uma breve consideração. Acta Paul Enferm. v.18, n. 4, p. 422-6; 2005.

20. MESQUITA, R. B. de., MORANO, M. T. A. P. et al. Rede de apoio social e saúde de idosos pneumopatas crônicos. Revista Ciência e Saúde Coletiva 17(5):1125-1133,2012.

21. MINAYO, M.C.S. Ciência, técnica e arte: o desafio da pesquisa qualitativa. In: Minayo MCS, organizadora. Pesquisa Social: teoria, método, criatividade. $21^{\text {a }}$ ed. Petrópolis (RJ): Vozes; 1994. p. 9-29.

22. MONTEIRO, P. M. J. Ansiedade e depressão na DPOC: O conhecimento actual, questões não respondidas e investigação necessária-- Revista Portuguesa de Pneumologia (English Edition) Volume 15, Issue 4, July-August 2009, Pag 740-742.

23. MOSCOVICI, S. A Invenção da Sociedade - Sociologia e Psicologia (Coleção Psicologia Social). M. Ferreira [trad.]. Petrópolis: Vozes. 2011.

24. OLIVEIRA, B. Psicologia do Envelhecimento e do Idoso. Porto: Livpsic, 2010.

25. OLIVEIRA F., VALE, R., et al. Efeitos do Grau de DPOC Sobre a Qualidade de Vida de Idosos. Fisioterapia em movimento. Curitiba, v. 22, n. 1, p. 87-93, jan./mar. 2009. 
26. OMS- Organização Mundial de Saúde. Envelhecimento Ativo: uma política de saúde. Brasillia: Organização Pan-Americana da Saúde, 2005.

27. PEREIRA, R. D. M., SILVA, W.W.O. da, et al. Práticas Integrativas e Complementares de Saúde: revisão integrativa sobre medidas não farmacológicas à dor oncológica. Rev. Enferm. UFPE on line., Recife, 9(2):710-7, fev., 2014.

28. PLEGUEZUELOS, E., PÉREZ, M. E., GUIRAO, L., AMITIER, B., COSTEA, M., ORTEGA, ..., MIRAVITLLES, M. (2013). Effects of whole body vibration training in patients with severe Chronic Obstructive. Respirology, 18(6), 1028-34.

29. PU, C. T., NELSON, M. E. Envelhecimento, função e exercício. In: FRONTEIRA, W. R.; Dawson, D. M.; Slovik, D. M. Exercício físico e reabilitação. Porto Alegre Artmed, 2001. Cap. 20, p.347-372.

30. REARDON, J., Casaburi, R., Morgan M. et al. Pulmonary rehabilitation for COPD. Respiratory Medicine 2005; 99: S19-S27. 